\title{
Genome-wide identification of Azospirillum brasilense Sp245 small RNAs responsive to nitrogen starvation and likely involvement in plant-microbe interactions
}

\author{
Vatsala Koul ${ }^{1,2+}$, Divya Srivastava ${ }^{2 \dagger}$, Pushplata Prasad Singh $^{2^{*}}$ and Mandira Kochar ${ }^{2^{*}}$ (D)
}

\begin{abstract}
Background: Small RNAs (sRNAs) are non-coding RNAs known to regulate various biological functions such as stress adaptation, metabolism, virulence as well as pathogenicity across a wide range of bacteria, mainly by controlling mRNA stabilization or regulating translation. Identification and functional characterization of sRNAs has been carried out in various plant growth-promoting bacteria and they have been shown to help the cells cope up with environmental stress. No study has been carried out to uncover these regulatory molecules in the diazotrophic alpha-proteobacterium Azospirillum brasilense Sp245 to date.

Results: Expression-based sRNA identification (RNA-seq) revealed the first list of $\sim 468$ sRNA candidate genes in A. brasilense Sp245 that were differentially expressed in nitrogen starvation versus non-starved conditions. In parallel, in silico tools also identified 2 of the above as candidate sRNAs. Altogether, putative candidates were stringently curated from RNA-seq data based on known sRNA parameters (size, location, secondary structure, and abundance). In total, $\sim 59$ significantly expressed sRNAs were identified in this study of which 53 are potentially novel sRNAs as they have no Rfam and BSRD homologs. Sixteen sRNAs were randomly selected and validated for differential expression, which largely was found to be in congruence with the RNA-seq data.

Conclusions: Differential expression of 468 A. brasilense sRNAs was indicated by RNA-seq data, a subset of which was confirmed by expression analysis. Four of the significantly expressed sRNAs were not observed in nitrogen starvation while 16 sRNAs were found to be exclusively expressed in nitrogen depletion. Putative candidate sRNAs identified have potential mRNA targets primarily involved in stress (abiotic and biotic) adaptability; regulation of bacterial cellular, biological and molecular pathways such as nitrogen fixation, polyhydroxybutyrate synthesis, chemotaxis, biofilm formation and transcriptional regulation. In addition to directly influencing bacteria, some of these sRNAs also have targets influencing plant-microbe interactions through adhesion of bacteria to plant roots directly, suppressing host response, inducing plant defence and signalling.
\end{abstract}

Keywords: Sstress response, sRNA, A. brasilense Sp245, RNA-seq, PGPB, sRNAscanner

\footnotetext{
* Correspondence: pushplata.singh@teri.res.in; mandira.kochar@teri.res.in

${ }^{\dagger}$ Vatsala Koul and Divya Srivastava contributed equally to this work.

${ }^{2}$ TERI Deakin Nanobiotechnology Centre, Sustainable Agriculture Division,

The Energy and Resources Institute, Gurugram-Faridabad Road, Gwal Pahari, Haryana 122003, India

Full list of author information is available at the end of the article
}

(c) The Author(s). 2020 Open Access This article is licensed under a Creative Commons Attribution 4.0 International License, which permits use, sharing, adaptation, distribution and reproduction in any medium or format, as long as you give appropriate credit to the original author(s) and the source, provide a link to the Creative Commons licence, and indicate if changes were made. The images or other third party material in this article are included in the article's Creative Commons licence, unless indicated otherwise in a credit line to the material. If material is not included in the article's Creative Commons licence and your intended use is not permitted by statutory regulation or exceeds the permitted use, you will need to obtain permission directly from the copyright holder. To view a copy of this licence, visit http://creativecommons.org/licenses/by/4.0/ The Creative Commons Public Domain Dedication waiver (http://creativecommons.org/publicdomain/zero/1.0/) applies to the data made available in this article, unless otherwise stated in a credit line to the data. 


\section{Background}

The Alphaproteobacterial class of Azospirillum include physiologically distinct, rhizosphere competent, plant growth-promoting bacteria (PGPB) that promote the growth of a wide range of plants through diverse, direct and indirect mechanisms [1,2]. Nitrogen fixation is not the most significant field function of this bacterial group, and it is the production of the plant growth regulators and their crosstalk which are the key signals for plant growth promotion effects [3-7]. Genome sequencing and analysis revealed that Azospirillum spp. which are now primarily established as plant-associated bacteria in the terrestrial habitat have actually transitioned from the aquatic environment $[8,9]$. For improved adaptation in the rhizosphere, nearly $50 \%$ of its genome has been horizontally acquired from distantly related terrestrial bacteria [representatives of Rhizobiales (alpha-proteobacteria) and Burkholderiales (beta-proteobacteria)]. The horizontally transferred (HGT) genes consist of genes encoding cellulolytic activity (required for penetration into plant roots), attachment (using Type IV pili), and chemotaxis operon, among other essential genes required for plant-microbe interaction [8].

Specific genes involved in rhizosphere adaptation suggest niche-specific responses of the strains [9]. It is extremely important to study the extent of influence and regulation of these microbial plant growth regulators so that their effect on plants can be judged for their appropriate action and application. Basic knowledge about the modulation of key physiological properties of such PGPBs is crucial for understanding diverse aspects related to rhizosphere performance, modes of action and successful interactions with plant roots. Bacteria possess various regulatory mechanisms for stress adaptation and to improve the stress enduring capability, it is important to gather in-depth information of the underlying physiological and molecular mechanisms as well as unravel the participating intermediates especially during stress attacks [10-13]. The ensuing cellular cascade in response to changing environmental conditions is not always completely understood due to the lack of information about regulatory molecules such as small RNAs which play an essential role at the post-transcriptional level [14]. This knowledge will also help kindle ideas about how to advance the production and application strategies in PGPB inoculants.

In the last couple of decades, genome-wide searches in different bacteria have led to the discovery of a plethora of small, non-coding regulatory RNA molecules (sRNAs), which possess the capability to regulate expression of multiple genes, transcriptional factors, sigma factors, and chaperones, leading to profound effect on the cell physiology [14-17]. The bacterial sRNAs identified till now are heterogeneous in size and range from 40 to
$550 \mathrm{bp}$, usually located in the intergenic regions and demonstrate a characteristic stem-loop secondary structure [18-22], though some exceptions exist [23]. A single bacterial genome is estimated to encode 200-300 sRNAs, possessing diverse functions such as plasmid replication [23], stress adaptation [24], regulating the expression of outer membrane proteins [25], iron homeostasis [26], quorum sensing [27] chemotaxis and biofilm formation [28], among others. Different studies have been carried out to discover sRNAs in plant-associated bacteria (PAB) like Sinorhizobium meliloti, Bacillus subtilis, Bradyrhizobium japonicum, Azotobacter vinelandii, and many others [29-34].

Azospirilla are the most well-known PGPB and consist of the strains Sp245, Sp7, and SM which are known to enhance the plant root morphology, specifically due to their two essential traits: biological nitrogen fixation (BNF) and biosynthesis of plant growth regulators (IAA, cytokinin, gibberellin, ethylene, and nitric oxide) [6, 3537]. The genome size of Azospirillum brasilense Sp245 (GC content: 68.5\%) is around $7.5 \mathrm{Mb}$ distributed in seven replicons-main chromosome and six plasmids (AZOBR_p1-p6). Although its genome is sequenced, no study has been carried out to identify the sRNAs in this organism. The genome sequencing of Azospirillum sp. B510 revealed putative genes for two types of small RNAs: the B subunit of RNaseP $(r n p B)$ and signal recognition particle RNA (ffs) [8], albeit no regulatory role has been associated with them so far.

In this study, we attempt to identify the sRNAs of $A$. brasilense Sp245 and quantify their transcription under nitrogen-limited conditions. Alongside genome-wide identification of novel sRNAs with follow-up Northern blots and qPCR, we provide a validated community resource for future studies. Many of these sRNAs may be involved in regulating important biological mechanisms such as plant growth regulators action, chemotaxis/motility, stress-responsive behaviour, nitrogen-metabolism, transcriptional regulation and plant association.

\section{Results}

\section{Plant growth-promoting trait evaluation}

Plant growth-promoting traits of A. brasilense Sp245 were investigated under various physiological conditions ranging from non-stressed to stressed nutrient conditions (predominantly carbon and nitrogen) to determine the variation in these traits which may be relevant in the rhizosphere niches for their functional behaviour. The results depicted in Table 1 indicate that polyhydroxybutyrate (PHB) production, NO production and Nitrogenase activity was significantly higher in both nutrient stress conditions in comparison to the non-stressed conditions while biofilm formation in nutrient stress conditions was not affected in strain Sp245. IAA production 
Table 1 Biochemical parameters of Azospirillum brasilense Sp245 under various physiological conditions ranging from non-stressed to stressed conditions reflecting the physiological competence of the strain

\begin{tabular}{|c|c|c|c|c|c|}
\hline Set & $\begin{array}{l}\text { Physiological } \\
\text { conditions }\end{array}$ & $\begin{array}{l}\mu \mathrm{g} \text { IAA/OD (IAA } \\
\text { production) }\end{array}$ & $\begin{array}{l}\mu \mathrm{g} \text { PHB/mg cell biomass } \\
\text { (PHB accumulation) }\end{array}$ & $\begin{array}{l}\mathrm{OD}_{560} \text { per cellular } \mathrm{OD}_{560} \text {-biofilm units } \\
\text { (Quantitative Biofilm formation) }\end{array}$ & $\begin{array}{l}\text { nmol/h (Ethylene Production, } \\
\text { Nitrogenase activity) }\end{array}$ \\
\hline $\mathrm{N} 1$ & $C+N$ & $16.27 \pm 0.046$ & $11.3 \pm 0.2$ & $11.94 \pm 1.26$ & 0.05 \\
\hline N2 & $\mathrm{C} / 2+\mathrm{N} / 2$ & $10.02 \pm 0.053^{a}$ & $54.2 \pm 0.4^{\mathrm{a}}$ & $13.02 \pm 1.86$ & $0.72^{\mathrm{a}}$ \\
\hline N3 & $C+N / 2$ & $14.34 \pm 0.028^{a}$ & $42.4 \pm 0.4^{a}$ & $13.68 \pm 0.98$ & $0.75^{\mathrm{a}}$ \\
\hline N4 & $\mathrm{C}-\mathrm{N}$ & & & & $0.39^{a}$ \\
\hline
\end{tabular}

The values represent the average of three independent sets \pm standard error from the mean

Statistical analysis was performed as described in Materials and methods

a, Values significantly different from strain Sp245 grown in set $\mathrm{N} 1$ at full strength $\mathrm{C}+\mathrm{N}$ at $P \leq 0.05$

IAA was quantified as mentioned previously. $1 \mathrm{mM}$ Trp was added to each culture at the time of subculture and the respective substrates were added after $6 \mathrm{~h}$ of growth

on the other hand was negatively influenced in both the nutrient stress conditions.

\section{sRNA sequencing and prediction}

RNA samples with high RIN value for VC (RIN 10) and VN (RIN 9.5) were used for RNA-seq. The cDNA libraries were prepared and proceeded for sRNA sequencing on an Illumina NextSeq500 platform (Illumina, USA). QC of the raw data files (VC_R1, R2 and VN_R1, R2) has been given in Additional File 1. The processed output files were aligned to the reference genome using Bowtie v2.1.0 [38]. During the alignment, in VC 100\% of the 5,513,335 reads were paired, out of which $4.57 \%$ were aligned concordantly zero times, $83.97 \%$ were aligned concordantly exactly one time and $11.46 \%$ were aligned concordantly more than one times. The total alignment rate obtained for $\mathrm{VC}$ and $\mathrm{VN}$ was 97.47 and $97.07 \%$ respectively. The summary of the outcome of each step of QC and differential expression analysis is shown in Table 2. By using Cufflinks, a total of $n=3860$ transcripts with a difference in expression levels were predicted in the two samples (Additional File 2) (Old AF4), of which $n=468$ had length between 50 and 500 bp under control and nitrogen-stress conditions (VC and VN, respectively). $N=59$ sRNAs showed significant differential expression (FDR corrected $p$-value 0.05) and also had transcript length between $50 \mathrm{bp}$ and $500 \mathrm{bp}$. and thus were further analysed for prediction of potential mRNA targets (Additional File 2). Of these sRNAs, 41 were up-regulated and 18 were downregulated in $\mathrm{VN}$ in comparison to VC (Table 3). The secondary structures prediction by Mfold for these 59 significantly expressed sRNAs revealed that all of them attained the complex stem-loop conformations which are characteristic of known bacterial sRNAs. These 59 sRNAs were further annotated and investigated for potential mRNA targets to understand the important pathways regulated by them under nitrogen stress.

Out of the total predicted 3860 candidates, 12 sRNAs were randomly selected and used in the validation process by northern blot analysis with probes mentioned in Additional File 3. It was observed that the selected 12

Table 2 Summary of sRNA sequencing analysis of Azospirillum brasilense Sp245

\begin{tabular}{|c|c|c|c|}
\hline S.No. & Steps & VN & VC \\
\hline \multirow[t]{2}{*}{1} & Total number of raw sRNA sequence reads & R1: 27200643 & R1: 16557793 \\
\hline & & R2: 27200643 & R2: 16557793 \\
\hline \multirow[t]{2}{*}{2} & Total number of Reads after Adapter removal and Quality filtering at q20 & R1: 7731698 & R1: 5513335 \\
\hline & & R2: 7731698 & R2: 5513335 \\
\hline 3 & Mapping percentage with reference genome (Azospirillum brasilense Sp245) & $97.07 \%$ & $97.47 \%$ \\
\hline 4 & Number of assembled reads (sRNA) & 15,614 & 15,424 \\
\hline 5 & Assembled sRNAs sorted based on size $50-500$ bp & 3838 & 3788 \\
\hline 6 & Total number of differentially expressed sRNAs in both samples VN \& VC (Additional File 2) & 3860 & \\
\hline 7 & No. of differentially expressed sRNAs, between 50 and 500 bp length, (Additional File 2) & 458 & \\
\hline 8 & $\begin{array}{l}\text { No. of significantly differentially expressed sRNAs } \\
\text { pvalue: }<0.05 \text { (with FDR) \& sRNAs length between } 50 \text { and } 500 \text { bp (Additional File 2) }\end{array}$ & 59 & \\
\hline 9 & No. of Downregulated sRNA genes (Table 3) & 18 & \\
\hline 10 & No. of Upregulated sRNA genes (Table 3) & 41 & \\
\hline
\end{tabular}

GenBank Assembly accession used for Bowtie: GCA 000237365.1

VC and VN imply strain Sp245 cells grown in SSM with the full strength of nitrogen and SSM with half strength of nitrogen, respectively 
Table 3 Differentially expressed sRNAs in controlled nutrient conditions (VC) versus nitrogen stress conditions (VN) in Azospirillum brasilense Sp245

\begin{tabular}{|c|c|c|c|c|c|c|c|c|c|}
\hline \multicolumn{5}{|c|}{ Upregulated sRNAs } & \multicolumn{5}{|c|}{ Downregulated sRNAs } \\
\hline sRNA_id & sRNA size & VC1 value & VN1 value & p_value & sRNA id & sRNA size & VC1 value & VN1 value & $\bar{p} \boldsymbol{p}$ _value \\
\hline AbSp_118 & 225 & 0 & 37.8556 & 0.00005 & AbSp_119 & 225 & 35.0559 & 2.83011 & 0.04805 \\
\hline AbSp_136 & 241 & 0 & 20.542 & 0.0019 & AbSp_124 & 228 & 4.43713 & 0 & 0.0344 \\
\hline AbSp_155 & 255 & 43.9049 & 207.732 & 0.0484 & AbSp_149 & 252 & 98.7514 & 1.16048 & 0.00055 \\
\hline AbSp_177 & 270 & 0 & 5.37379 & 0.039 & AbSp_159 & 258 & 1100.41 & 9.23603 & 0.0018 \\
\hline AbSp_189 & 279 & 18.3086 & 556.103 & 0.00255 & AbSp_160 & 258 & 5.46297 & 0 & 0.01445 \\
\hline AbSp_19 & 90 & 0 & 21.5451 & 0.02095 & AbSp_178 & 270 & 25.8129 & 4.6556 & 0.04725 \\
\hline AbSp_193 & 282 & 42.0717 & 3283.41 & 0.00035 & AbSp_220 & 300 & 68.0688 & 10.5244 & 0.04105 \\
\hline AbSp_194 & 282 & 630.942 & 7287.28 & 0.02545 & AbSp_252 & 324 & 2.8567 & 0 & 0.0344 \\
\hline$A b S p \_2$ & 74 & $19,184.8$ & 224,650 & 0.0091 & AbSp_264 & 330 & 58.9137 & 9.8017 & 0.031 \\
\hline AbSp_214 & 297 & 45.2875 & 397.939 & 0.03035 & AbSp_293 & 363 & 237.893 & 30.1123 & 0.03395 \\
\hline AbSp_219 & 300 & 0 & 5.14205 & 0.0208 & AbSp_332 & 396 & 21.2397 & 3.05772 & 0.01735 \\
\hline AbSp_239 & 315 & 20.0026 & 515.628 & 0.0033 & AbSp_382 & 441 & 259.241 & 38.0665 & 0.0494 \\
\hline AbSp_257 & 326 & 58.2017 & 847.189 & 0.009 & AbSp_39 & 183 & 10.8689 & 0 & 0.01445 \\
\hline AbSp_268 & 333 & 22.4175 & 921.357 & 0.0015 & AbSp_391 & 450 & 39.8958 & 3.30199 & 0.00575 \\
\hline AbSp_29 & 165 & 27.5982 & 1100.28 & 0.00495 & AbSp_410 & 462 & 141.891 & 15.8314 & 0.0264 \\
\hline AbSp_294 & 363 & 0 & 2.71895 & 0.039 & AbSp_450 & 498 & 26.0091 & 3.96386 & 0.04145 \\
\hline AbSp_308 & 375 & 46.3089 & 1225.36 & 0.0029 & AbSp_51 & 189 & 75.8142 & 12.4539 & 0.0439 \\
\hline AbSp_313 & 379 & 25.3495 & 654.802 & 0.00445 & AbSp_73 & 201 & 9514.16 & 639.783 & 0.0073 \\
\hline AbSp_314 & 381 & 0 & 3.1861 & 0.00355 & & & & & \\
\hline AbSp_324 & 387 & 42.9103 & 368.276 & 0.023 & & & & & \\
\hline AbSp_336 & 402 & 18.0015 & 155.195 & 0.0307 & & & & & \\
\hline AbSp_343 & 408 & 98.3318 & 595.871 & 0.04125 & & & & & \\
\hline AbSp_345 & 411 & 3.53559 & 30.7108 & 0.04255 & & & & & \\
\hline AbSp_347 & 414 & 253.799 & 2065.6 & 0.04155 & & & & & \\
\hline AbSp_355 & 420 & 5.51417 & 255.763 & 0.0127 & & & & & \\
\hline AbSp_359 & 423 & 0 & 4.64154 & 0.0114 & & & & & \\
\hline AbSp_38 & 183 & 453.436 & 8048.83 & 0.01165 & & & & & \\
\hline AbSp_390 & 450 & 6.91909 & 1152.3 & 0.0025 & & & & & \\
\hline AbSp_409 & 462 & 4.64182 & 137.132 & 0.0083 & & & & & \\
\hline AbSp_419 & 471 & 12.6331 & 220.605 & 0.0047 & & & & & \\
\hline AbSp_445 & 492 & 0 & 9.78685 & 0.00165 & & & & & \\
\hline AbSp_449 & 498 & 20.2349 & 841.26 & 0.00065 & & & & & \\
\hline AbSp_45 & 186 & 0 & 193.89 & 0.0001 & & & & & \\
\hline AbSp_58 & 192 & 0 & 117.01 & 0.0001 & & & & & \\
\hline AbSp_59 & 192 & 0 & 10.2805 & 0.006 & & & & & \\
\hline$A b S p \_64$ & 195 & 0 & 11.1888 & 0.006 & & & & & \\
\hline AbSp_65 & 195 & 0 & 3.64177 & 0.02095 & & & & & \\
\hline AbSp_66 & 195 & 0 & 4.41882 & 0.02095 & & & & & \\
\hline AbSp_67 & 195 & 8.7278 & 108.935 & 0.0322 & & & & & \\
\hline$A b S p \_8$ & 76 & 3224.96 & $44,002.6$ & 0.01065 & & & & & \\
\hline AbSp_93 & 210 & 0 & 7.97932 & 0.0208 & & & & & \\
\hline
\end{tabular}


sRNAs were expressed under both the non-stressed (control conditions (VC) as well as nitrogen stressinduced conditions $(\mathrm{VN})$. Apart from conforming to the known sRNA parameters (such as location and size), they possessed high FPKM values since that would make their detection possibly easy. Northern blot analysis revealed that all 12 sRNAs showed a single band (Additional File 3).

\section{In-silico identification of novel sRNAs}

In parallel to the RNA-seq analysis, sRNAscanner was used to scan the multi-replicon genome of $A$. brasilense Sp245 (GenBank Assembly accession: GCA_0002373 65.1) to predict putative sRNAs. Two sRNAs labelled AbSp_464 (location: AZOBR_p4; NC_016596, sRNA locus: NC_016596.1:167096-167,348) and AbSp_465 (Location: AZOBR_p6; NC_016597 sRNA locus: NC_ 016597.1:36503-85,307) were predicted (Table 4). Both the computationally predicted sRNAs, AbSp_464 and AbSp_465 were also validated by Northern blotting (Additional File 3).

\section{Annotation of sRNAs}

For preliminary functional annotation, the sRNA sequences were searched against the Rfam database and BSRD. Rfam database is a collection of RNA families comprising of non-coding RNA genes, structured cisregulatory elements and self-splicing RNAs, while BSRD is a repository for bacterial small regulatory RNAs. A total of 4 of the 59 uncovered sRNAs in our study showed homology with previously reported sRNAs in BSRD while 2 entries show homology to the tRNA family in Rfam (Table 5, AbSp_39, AbSp_308, AbSp_345, AbSp_93, AbSp_2, AbSp_8), which also supports the finding that all the other identified sRNAs are likely to be novel.

\section{Conserved motifs and promoter prediction}

All 59 sRNA sequences were used for motif prediction using MEME at default parameters, and the top 3 motifs were selected based on high score, length ( $>9$ nucleotides), and $p$-value $(<1 \mathrm{e}-10)$. The results indicated that sRNAs share common motif sequences (Additional File 4). Searching these motifs in the motif database using a comparison tool, TOMTOM [39] revealed that motif
M1 possessed homology with the transcriptional regulator AlgR which controls a variety of virulence factors, including alginate production, twitching motility, biofilm formation, and hydrogen cyanide production in Pseudomonas aeruginosa [40]. Motif M2 shares similarity with Escherichia coli RutR which is the master regulator of genes involved in pyrimidine catabolism [41] while motif M3 was homologous to the motif present in the transcriptional factor, Pseudomonas sigma regulator (PsrA) involved in bacterial epiphytic fitness, quorum sensing and plant interactions [42].

BPROM [43] predicted the presence of one promoter each in the upstream region of 19 sRNAs, while no promoters could be predicted for other significantly expressed sRNAs (Additional File 4). Additionally, AbSp_465 revealed the presence of a RpoD17 binding site at position 96 for the promoter predicted at position 77. For AbSp_459 presence of RpoD19 and RpoD17 binding sites were observed at positions 570 and 574, respectively for the promoter predicted at position 588 . For other sRNAs with predicted promoters, no known sigma-factor binding sites (within $500 \mathrm{bp}$ upstream region) were observed for their promoters.

\section{Prediction of target mRNA}

Target prediction for the selected 59 sRNAs was done using IntaRNAv2.0 [44]. In total, 56 different gene targets were predicted (which fall under different functional categories) for the 59 sRNA candidates (Additional File $5)$. Many of these targets $(\sim 20)$ are known to be involved in plant-microbe association and interactions at varying levels. Some of the gene targets were significantly frequent among the differentially expressed 59 sRNAs (Fig. 1a). The highly enriched category included $A B C$ proteins, which included $A B C$ transporter proteins, ATP-binding protein, $A B C$ transporter permease, $A B C$ transporter substrate-binding protein, Amino acid $A B C$ transporter permease, Amino acid $\mathrm{ABC}$ transporter substrate-binding protein, iron $\mathrm{ABC}$ transporter permease and iron $A B C$ transporter substrate-binding protein and was commonly predicted for 31 of the identified 59 sRNA candidates. The next prevalent category consisted of transcriptional regulators including $\mathrm{AbrB}, \mathrm{AsnC}$, XRE, GntR, IclR, LysR, MarR, MarC, TetR/AcrR families of transcriptional regulators and was shared between 15

Table 4 Details of the sRNAs predicted by in silico analysis with sRNAscanner

\begin{tabular}{lllll}
\hline sRNA & $\begin{array}{l}\text { Genomic } \\
\text { Location }\end{array}$ & Position & Sequence (5'-3') & $\begin{array}{l}\text { Length } \\
\text { (bp) }\end{array}$ \\
\hline AbSp_ & Plasmid, & NC_016596.1: & TGTGTTTTAAATGGATGTGCGAATTCTATTGTTTGTTATCAGCGGTTTG & 49 \\
$464^{\mathrm{a}}$ & AZOBR_p4 & $167096-167,348$ & & \\
AbSp_ & Plasmid, & NC_016597.1: & TGACAATGCAAAGACCGTCTCCTTTCCGCAATCAAACAAGAAGAAAATGCCCTCGCTCTATTCCTAC & 103 \\
$465^{\mathrm{a}}$ & AZOBR_p6 & $36503-85,307$ & ACTCGGTGAGCGCTGTTCCGTCGAGCTGGCAGCC & \\
\hline
\end{tabular}

These sRNA were also identified through RNA-seq analysis 
Table 5 Azospirillum brasilense Sp245 sRNAs with homologs in BSRD and homology with Rfam families

\begin{tabular}{llllllll}
\hline sRNA Id & sRNA gene ID & Subject & Strain name & Score & E-value & $\begin{array}{l}\text { Alignment Length / } \\
\text { homology (\%) }\end{array}$ & Function \\
\hline AbSp_39 & AZOBR_RS26955 & sgur2698.1 & Geobacter uraniireducens Rf4 & 34.2 & 0.036 & 100 & Cyclic di-GMP-II riboswitch \\
AbSp_308 & AZOBR_RS37495 & scch1500.1 & Chlorobium chlorochromatii CaD3 & 36.2 & 0.021 & 100 & Regulatory element \\
AbSp_345 & AZOBR_RS30660 & ssme817.1 & Sinorhizobium meliloti 1021 & 36.2 & 0.019 & 100 & cis-encoded antisense RNA \\
AbSp_93 & AZOBR_RS24525 & sec0498.1 & Escherichia coli K12 MG1655 & 50.1 & $7.00 E-07$ & 96 & Trans-encoded antisense RNA \\
AbSp_2 & AZOBR_RS36450 & RF0000 & -NA & 63.1 & $1.20 E-14$ & 100 & tRNA family \\
AbSp_8 & AZOBR_RS18695 & RF00005 & -NA & 60.2 & $7.90 E-14$ & 100 & tRNA family
\end{tabular}

candidate sRNAs. The gene-class and frequency of putative mRNA targets relevant for plant-microbe interactions were compared between groups of sRNA candidates with (a) upregulated expression in VN (Fig. 1b) and (b) down-regulated expression in VN (Fig. 1c). $\mathrm{ABC}$ transporters, transcriptional regulator proteins, Histidine based regulatory proteins (including lyase, kinases response regulators etc.), DNA binding response regulator and glycosyltransferases were commonly shared target protein families between the sRNAs that were either upregulated or down-regulated on exposure to nutrient stress in sample VN. Noticeably, targets of preferentially downregulated sRNAs included the transcriptional regulator protein MarC, methyl-accepting chemotaxis protein and DUF-domain (EAL domain) containing proteins were preferentially predicted for the group of sRNAs showing significantly downregulated expression in VN.

On the other hand, targets favourably predicted for the upregulated sRNA in VN included the flagellar basal body rod protein, membrane protein and hemindegrading factor (Additional File 5). This could imply towards increased motility under nitrogen stress conditions leading to improved colonization of host plant roots and better establishment of the bacterium in the root niches. With the target flagellar basal body rod protein FlgC, AbSp_2 and AbSp_93 could negatively regulate the motility of $A$. brasilense by regulating flagella structural components. A similar response has been observed in Salmonella enterica [45].

Fourteen of the 59 significantly differentially expressed candidate sRNAs were coded by non-protein-coding genes as no InterProScan search hits were found (Additional File 6). From these 14 sRNAs, a large proportion may likely be novel sRNAs with no known sRNA homology. Target prediction output for sRNAs from non-protein-coding loci of A. brasilense Sp245 suggested $\mathrm{ABC}$ transporter proteins, histidine ammonia-lyase, transcription regulators and hemin degrading factor as the prominent targets (Fig. 2, Additional File 6). Interestingly, 6 of these were upregulated while 8 were downregulated in nitrogen stressed conditions in A. brasilense Sp245. These may likely be involved in the nutrient stress response and consequent regulation of the bacterial physiology. Altogether, the sRNA targets prediction suggested possible comprehensive involvement of the sRNAs in the regulation of various essential bacterial biological networks and plant growth influencing functions such as those mentioned in Fig. 3. Functional evaluation of a selected few candidate sRNAs is being taken up in our lab and may also be the focus of future studies of different research groups.

\section{Validation of differential expression of sRNAs}

Sixteen sRNAs out of a total of 59 were selected for validation by quantitative RT-PCR. These sRNAs were selected based on (i) highly significant differential expression between VC and VN (unstarved versus nitrogen starved conditions) or (ii) role in the regulation of important mRNA targets. The selected sRNAs and primers designed are shown in Additional File 7 and the results of differential expression analysis are shown in Fig. 4. Generally, the trend observed with RNA-seq data was also observed with the qRT-PCR analysis. Further, the 4 sRNAs (AbSp_124, AbSp_160, AbSp_252 and AbSp_39 did show very low or almost negligible expression along with the downregulated AbSp_119 and AbSp_149 sRNAs. AbSp_118, AbSp_136, AbSp_2 and AbSp_449 were found to be significantly expressed in nitrogen starvation response of $A$. brasilense Sp245. Other upregulated nitrogen starvation responsive sRNAs were AbSp_59, AbSp_64, AbSp_65, and AbSp_464 (Fig. 4). AbSp_465 did not show a significant fold change in expression even though RNA-seq data seemed to indicate that it is nitrogen starvation responsive sRNA This warrants further investigation and may be due to an interplay with other regulatory molecules.

\section{Discussion}

In order to survive in the rhizosphere, the microorganisms need to constantly adapt to the changing environment. These environmental conditions, for example, change in temperature, nutrition, $\mathrm{pH}$, salt concentration etc., may sometimes be favourable or otherwise pose a challenge and induce stress responses in the bacteria [46]. The IAA produced in nutrient stressed conditions 
A

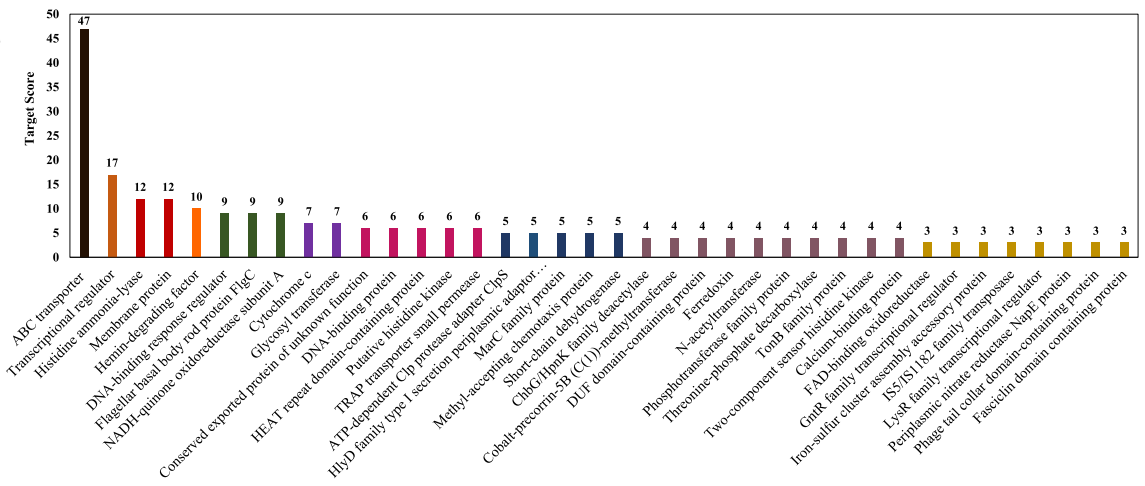

Target Name

B

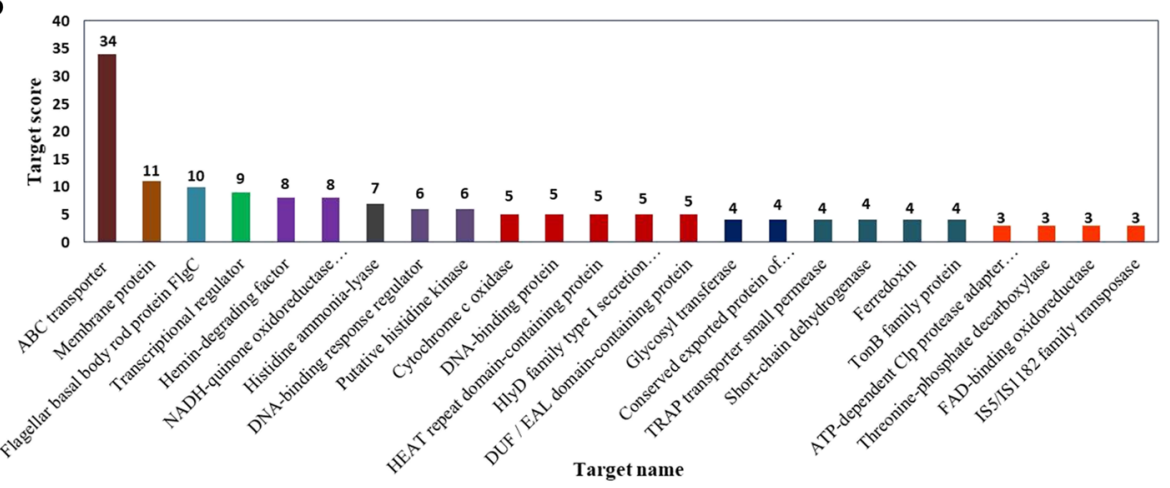

C

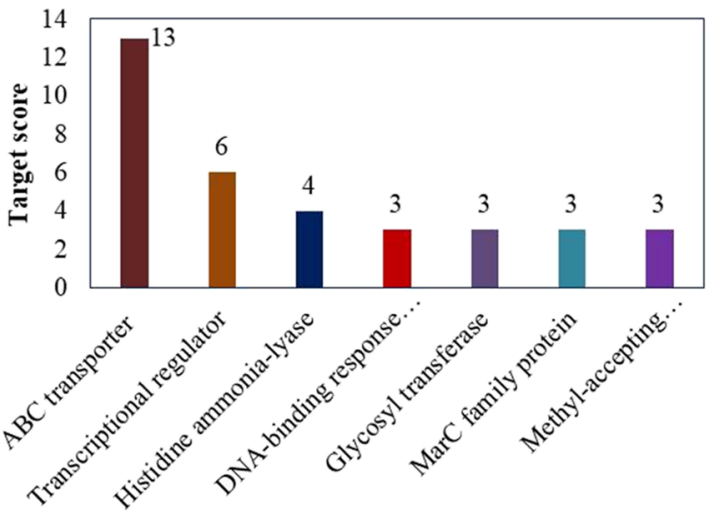

Target name

Fig. 1 Targets predicted for each of the 59 candidate sRNAs identified in this study (a). The gene-class and frequency of putative mRNA targets relevant for plant-microbe interactions was compared between sRNA candidates with upregulated expression in VN (b) and downregulated expression in VN (c). For ease of graphical representation, only those targets with score $\geq 3$ are shown. For further details please see Additional File 5

by strain Sp245 have been observed to be significantly lower while the nitrogenase activity and PHB produced by the strain were significantly higher than in unstressed conditions. As such the IAA and PHB production is known to be regulated or enhanced in nutrient deficiency in A. brasilense Sp245 [47, 48]. The bacterial defence mechanism is usually a cascade of events with multi-layer regulation. The ensuing cellular cascade in response to environmental stresses is not always completely understood due to insufficient information of 


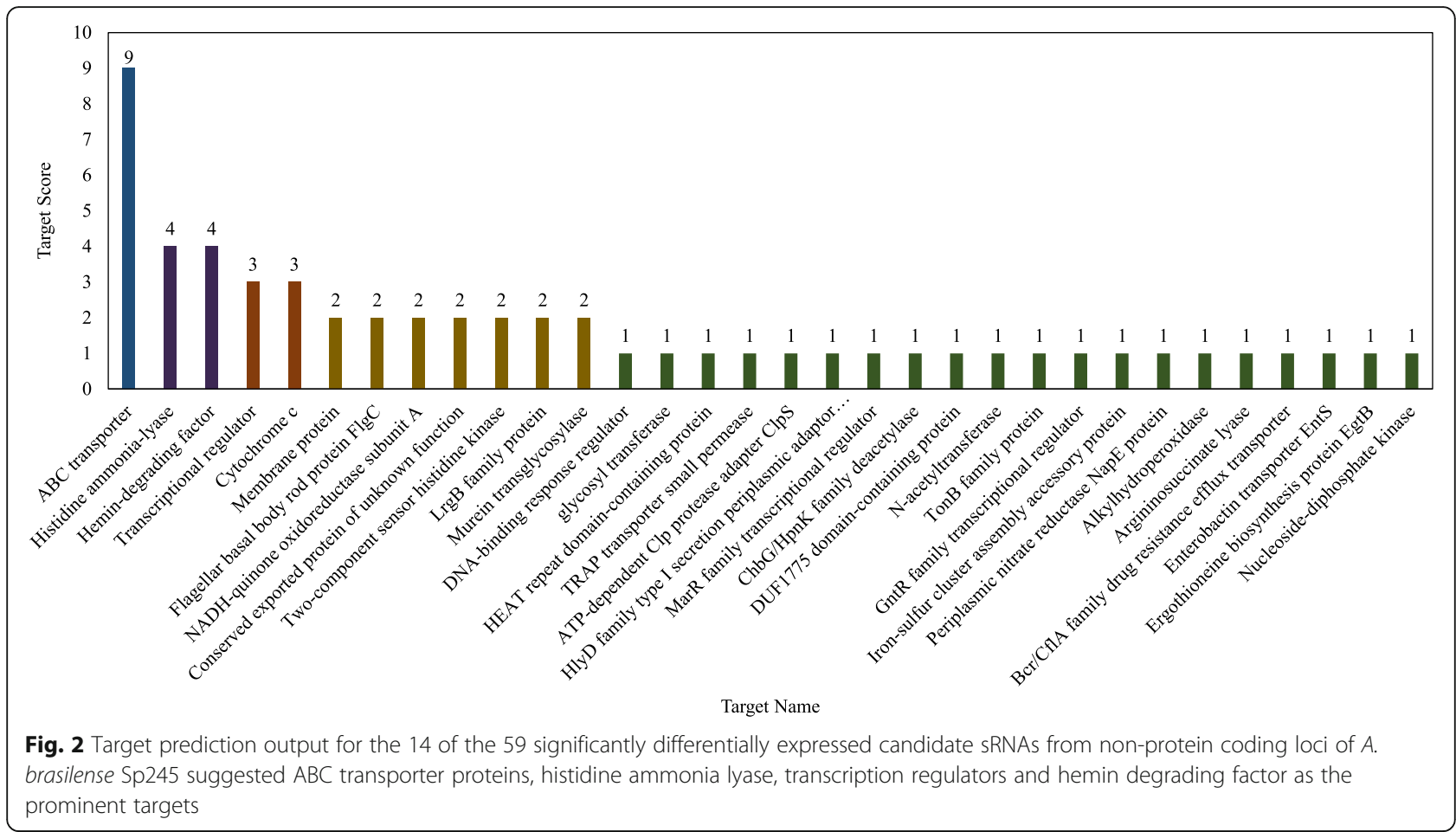

regulatory molecules which play an essential role at the post-transcriptional level. The cumulative impact of all the members of the complex regulatory network enables the bacterial cells to adapt and survive under a dynamic environment [24, 49]. Various studies have exploited the RNA-seq approach to reveal previously undetected small RNAs across numerous bacterial and cyanobacterial species including strains of Pseudomonas aeruginosa, $P$. putida and P. syringae [50, 51], Neisseria gonorrhoeae, Salmonella enterica and Streptococcus pyogenes [52-55], Vibrio cholerae [56, 57], and Synechocystis sp. PCC6803 [58]. A genome-wide search for novel regulatory RNAs and identified sRNA RyhB, in the model organism, $E$. coli, which was later, found to regulate the expression of genes in iron homeostasis $[25,26]$. The efficiency and sensitivity of the existing sRNA prediction tools can be improved by suitably modifying their algorithm in accordance with the bacterial genome of interest. A recent exercise of modulation of existing sRNA prediction tools with Agrobacterium strains led to the prediction of 384 sRNAs [59]. We thus used a combinatorial approach involving RNA-seq and computational tools for genomewide detection of sRNAs in the A. brasilense Sp245 bacterial genome. The RNA-seq data analysis indicate the presence of many novel sRNAs in A. brasilense Sp245. Additionally, 2 sRNAs (AbSp_464 and AbSp_465) were also recovered through in-silico analysis. The identification of both these sRNAs from RNA-seq data is note-worthy.

Differential RNA-seq (dRNA-seq) led to the identification of genome-wide transcriptional start sites (TSSs) and differentially expressed genes in gram-positive PGPR Bacillus amyloliquefaciens subsp. plantarum FZB42, grown under different rhizosphere-mimicking conditions (in the presence of root exudate and soil extract). This study also revealed 86 sRNA candidate genes, of which 13 were previously known sRNAs [34]. Out of 86 potential candidates, only 19 candidates could be detected as distinct transcripts. Whole-genome survey of Sinorhizobium meliloti by deep-sequencing revealed that $3 \%$ of its genes code for trans-encoded sRNAs [60]. A study using nutrient starvation stress response as the key physiological indicator in Salmonella enterica SL1344 and confirmed that 63 sRNAs are differentially expressed in this bacteria in different growth conditions [53]. Out of these, many are involved in varying degrees in the carbon-starvation stress response of the bacterium. In lines with these results, our study also reports the discovery of $\sim 468$ differentially expressed candidate sRNAs from non-stressed vs. nitrogen-starved $A$. brasilense Sp245 cells. Of these, 59 sRNAs are differentially expressed (41 sRNAs upregulated and 18 downregulated sRNAs) with 16 sRNAs being exclusively expressed in nitrogen starvation and 4 sRNAs not being expressed in 


\section{Transporters (nutrients)}

AbSp_65, AbSp_268, AbSp_308, AbSp_409, AbSp 2, AbSp_8, AbSp_38, AbSp_45, AbSp_58, AbSp_67, AbSp_66, AbSp_64, AbSp_93, AbSp_155, AbSp_177, AbSp_193, AbSp_214, AbSp 239, AbSp_314, AbSp_321, AbSp_336, AbSp_345, AbSp_347, AbSp_409, AbSp_419, AbSp_465, AbSp_39, AbSp_159, AbSp_178, AbSp_293AbSp_382, AbSp_391, AbSp_410, AbSp_450, AbSp_264, AbSp_332

\section{Siderophores / iron metabolism} AbSp_465, AbSp 59 AbSp_355, AbSp_391

Nitrogen fixation and metabolism AbSp_465, AbSp_449, AbSp_66, AbSp_257, AbSp 332 Biocontrol AbSp 136, AbSp 64, AbSp_252, AbSp_382

Withstanding hostile environments

/Stress response molecules/polymers AbSp 59, AbSp_194, AbSp_464, AbSp_65, AbSp_268, AbSp_308, AbSp_264, AbSp 332

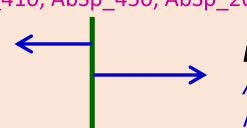

ation, Exopolysaccharid AbSp_464, AbSp_189, AbSp 239, AbSp_314, AbSp 59, AbSp_65, AbSp_118, AbSp_449, AbSp_149, AbSp_159, AbSp_410

Molecular chaperones AbSp_464

Transcriptional Regulators AbSp_45, AbSp_409, AbSp_465, AbSp_73, AbSp_220, AbSp_382, AbSp_124,AbSp_149, AbSp_391, AbSp_159, AbSp_178, AbSp_293

Chemotaxis, flagellar motility, Chemoreceptor binding AbSp 2, AbSp 93, AbSp_19, AbSp_38, AbSp_58, AbSp_67, AbSp_118, AbSp_177, AbSp_359, AbSp_314, AbSp_343, AbSp_419, AbSp_464, AbSp_73, AbSp_220, AbSp_149

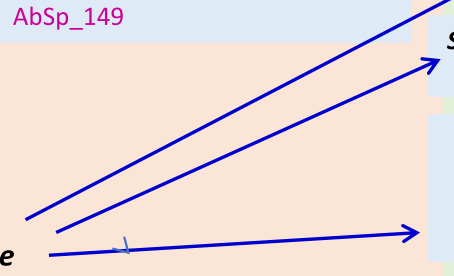

Azospirillum brasilense

Sp245

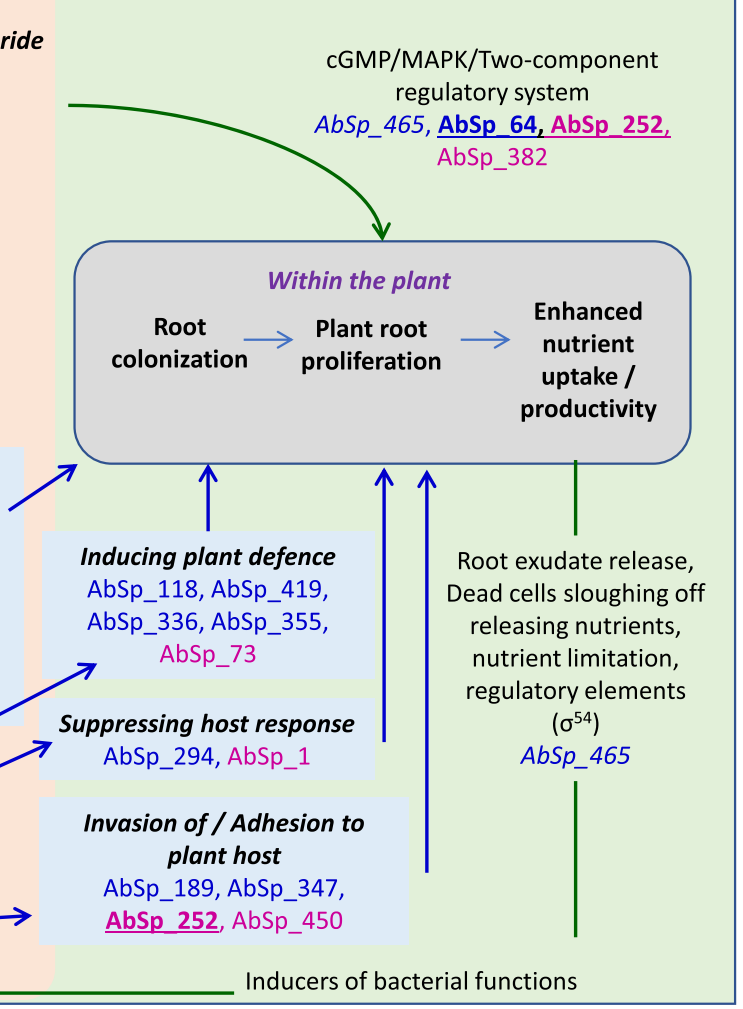

Fig. 3 Model highlighting 60 sRNAs from A. brasilense Sp245 with predicted targets likely to influence plant association, colonization, productivity as well as regulation of various essential bacterial biological networks and plant growth influencing functions. sRNAs with upregulated targets are highlighted in blue while those that have downregulated targets are indicated in pink. The sRNAs from non-protein coding loci are underlined nitrogen depletion conditions. 53 of the 59 are potentially novel sRNAs as they bear no BSRD or Rfam homology and 16 have been functionally validated for differential expression.

To identify the biological function of the bacterial sRNAs, use of an in-silico approach for target prediction is commonly conducted to recognize potential mRNA targets and thereby the regulatory networks influenced by the sRNA. P. aeruginosa has been shown to possess iron-responsive sRNAs, PrrF1 and PrrF2 [61], and heme-responsive sRNA, PrrH [62]. This study employed an approach similar to ours, to determine potential targets of PrrH and subsequently, its involvement in virulence was hypothesized. The regulatory RNAs in Actinobacillus pleuropneumoniae were predicted using multiple in-silico tools and post their experimental validation; the possible mRNA targets were investigated to identify the pathways in which the sRNAs might be functional [63].
It is likely that $A$. brasilense candidate sRNAs of the $\operatorname{mar} C$ target gene may be involved in the stress response regulation of $A$. brasilense. DUF or the GGDEF domains are involved in processing cyclic-di-GMP, a universal bacterial second-messenger molecule $[64,65]$. Cyclic-diGMP is critical to the regulation of key bacterial functions are motility, chemotaxis, capsular polysaccharide formation, biofilm formation and cellulose synthesis [66]. The Azospirillum genomes encode a large number of proteins that are likely involved in cyclic-di-GMP metabolism and these together regulate host specificity and environment-specific adaptation of the bacteria in the soil niches. Whether cyclic-di-GMP physiologically regulates the $m c p$ gene and other genes involved in chemotaxis is yet to be seen. Further studies would be needed to confirm this.

Located between a metallo-dependent amidohydrolase and the sulphite exporter TauE (also a DUF family protein), the probable mRNA targets of AbSp_136 were 


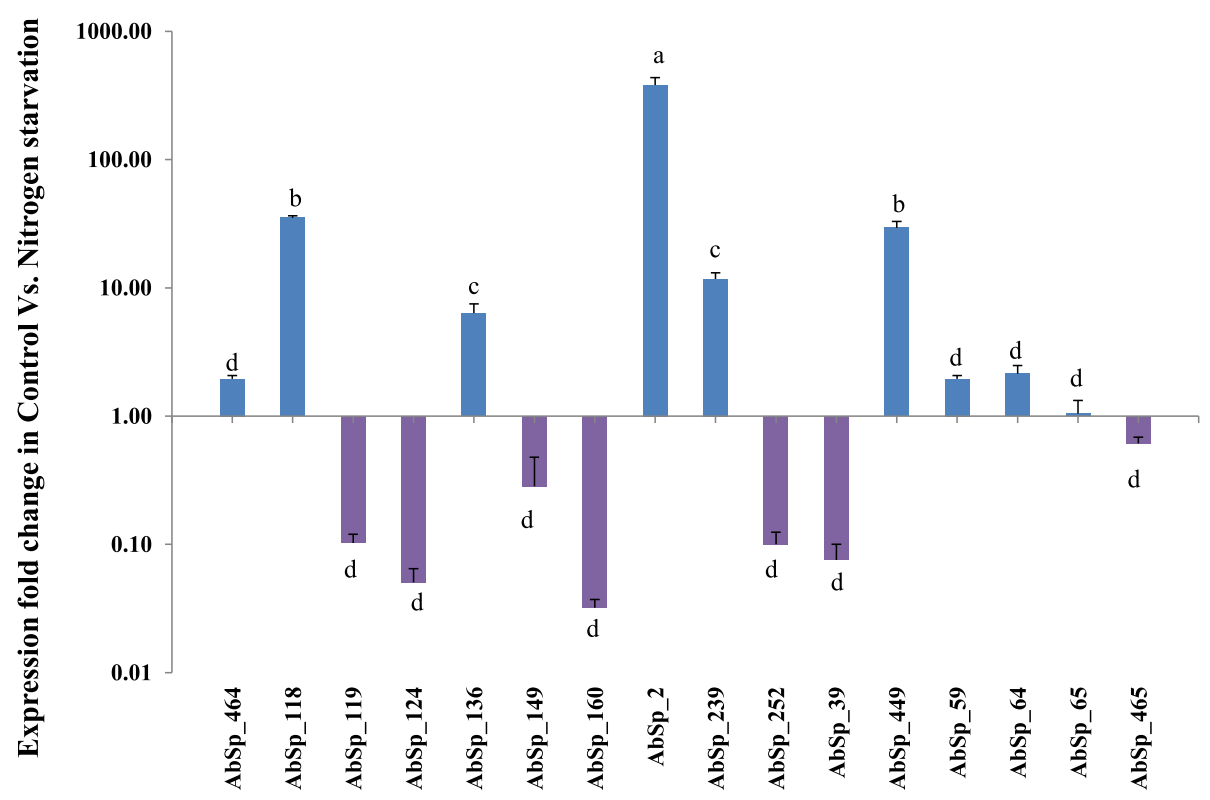

Azospirillum brasilense Sp245 sRNAs

Fig. 4 Differential expression validation of selected sRNAs by quantitative real time PCR. The mean of normalized expression fold change data of 3 replicates is reported along with the standard error from mean. The data was statistically analysed for variance by ANOVA followed by Duncan's Post hoc analysis at $P \leq 0.05$. Note: ${ }^{a}, b, c, d$ reflect the significance in sRNA expression in nutrient starvation at $P \leq 0.05$

protein export membrane protein, enterobactin transporter, hemin-degrading factor and the LgrB family protein. Enterobactin is a string Fe (III) chelator thereby helping bacteria scavenge Fe and hydroxyl groups (hydrolyzed enterobactin) not only to meet their critical requirement but simultaneously reduce oxidative stress [15]. LgrB is a paralog of the $\lg r E$ gene (large GC rich genes belonging to the DUF family) which is related to Nucleotide-binding Oligomerization Domain (NOD) containing proteins involved in regulating apoptosis and phytopathogen resistance ( $R$ genes) in plants.

Overall, the model presented in Fig. 3 highlights the sRNAs from $A$. brasilense Sp245 which have predicted targets with the potential to influence plant association, colonization, productivity as well as modulation of bacterial and plant physiology in plant-microbe association conditions. These include nitrogen-fixation and utilization, siderophores and iron homeostasis, biofilm formation, exopolysaccharide production, nutrient transporters, high-temperature stress adaptability, capability to withstand hostile environments and stress responsive behaviour (including the carbon storage polymer, poly hydroxyl butyrate production), chemotaxis/motility, adhesion to plant roots, induction of plant defence and suppression of plant response and transcriptional regulation. There are possibly over 60 sRNAs with likely involvement in plant association and growth promotion alongside plant-microbe interactions. It is also likely that many of the candidate sRNAs that are not differentially expressed in nutrient starvation conditions may still have a regulatory role in plant-microbe interactions and traits relevant to the same, either directly or through $\mathrm{Hfq}$ pairing or antisense base - pairing. It is hence a strong possibility that further experimental evidence may confirm that the number of sRNAs involved in Azospirillum-plant interaction may be even greater than those identified in this study.

The eubacterial sRNAs generally do not contain expressible ORFs, although some of them, such as SgrS or RNAIII of Escherichia coli or Staphylococcus aureus, also contain coding regions [16]. It may also be the case with some of the sRNAs identified in this study from $A$. brasilense Sp245. The characteristic stem-loop, secondary structure of the sRNAs protects the molecule and essentially its binding sites from RNase degradation within the cellular environment. The presence of rho-independent terminators is a well-documented phenomenon for Hfq-dependent sRNAs [67-69], and only in case of 3 sRNAs terminator sequences could be predicted, suggesting the dependence of these 3 sRNAs on the RNA chaperone (Hfq, AbSp_67, AbSp_149 and AbSp_159). For the remaining sRNA either 
independence of $\mathrm{Hfq}$ or the presence of some additional mechanism for Hfq-sRNA interaction may well be observed when studied in greater detail.

The bacterial sRNAs were initially not known to possess recurrent or conserved nucleotide motifs [70], however, recent studies have revealed that certain sRNA families contain protein binding motifs to inhibit the interaction of the protein with their target mRNAs. Also, sRNAs possessing a common motif in their binding sites suggest them to have similar target mRNAs [16]. The function of the sRNA can primarily be judged by the presence of conserved motifs and the promoters. The motif prediction of the 59 significantly expressed sRNAs revealed that they shared common motif sequences (M1, M2 and M3), which possessed homology with essential bacterial transcriptional regulators which influence cellular mechanisms such as chemotaxis, biofilm formation, quorum sensing, plant interaction, virulence, among many others [71]. The presence of such master transcriptional regulation motifs corroborated the role of sRNAs identified in our study as putative global regulators which may influence essential cellular cascades in the physiology and function of plant growth-promoting bacteria.

The sRNA promoters are sensitive to environmental fluctuations and regulate the sRNA expression in response to stress [14]. A recent study has revealed that the properties of the sRNA promoter influence the negative feedback circuit existing between two-component systems, EnvZ-OmpR and the sRNAs OmrA/B [72]. The promoter prediction uncovered the presence of one promoter each in the upstream region of 19 sRNA sequences, and sRNAs AbSp_465 and AbSp_459 possessed RpoD binding sites. RpoD is a primary sigma factor expressed during exponential growth and preferentially transcribes genes associated with fast growth, such as ribosomal operons and other protein-synthesis related genes. Further studies corroborating the functional characterization of the sRNAs are required to establish and enhance our understanding of the underlying mechanism of stress adaptability in Azospirillum and its interaction with various host plants.

\section{Conclusions}

Over the years the sRNA identification in PAB and their expression study under different growth conditions, and their functional characterization have improved the knowledge of bacteria-host interactions. We have integrated an RNA-seq and in silico sRNA identification approach to generate the first list of candidate sRNAs in the well-known PGPB, A. brasilense Sp245. These have been curated in non-starved and nitrogen starved conditions and observations made point towards the regulatory role of the identified and validated sRNAs in $A$. brasilense Sp245 in not only bacterial stress tolerance but also plant-microbe association and interactions leading to plant growth promotion. The comprehensive analysis of the candidate sRNAs presented in this paper highlights the existence of functionally important sRNAs in non-stressed and nitrogen starvation conditions in $A$. brasilense Sp245. This research will stimulate further work in the field of PGPB, improvement of their efficacy and subsequent development of improved Azospirillumbased bioformulations which could further reduce the use of chemical fertilizers and enhance the productivity of the associated plants exposed to abiotic stress.

\section{Methods}

\section{Bacterial strain, media and growth conditions}

A. brasilense Sp245 (obtained from Prof. Gladys Alexandre, The University of Tennessee, USA) was used in this study. The bacterial culture was maintained on Luria-Bertani agar with $50 \mu \mathrm{g} / \mathrm{ml}$ ampicillin. The purity of the culture was checked periodically on modified nitrogen-free basal $(\mathrm{OAB})$ medium as described [73]. For all experiments, an initial $\mathrm{OD}_{560}$ of 0.1 (unless otherwise stated, $\sim 2 \times 10^{7} \mathrm{cfu} / \mathrm{ml}$ ) was maintained by subculturing the overnight-grown culture of strain Sp245 (18 h) in $20 \mathrm{ml}$ of buffered standard succinate medium (SSM) [74]. The cells were grown at $30^{\circ} \mathrm{C}, 180 \mathrm{rpm}$ for all experiments.

\section{Plant growth-promoting trait evaluation}

The PGPR traits relevant for plant growth were evaluated by quantifying the plant growth regulator, IAA; nitrogenase activity, poly- $\beta$-hydroxybutyrate (PHB) production and biofilm formation. IAA produced by the bacteria was quantified according to $[6,75]$. The three conditions were: SSM with full strength Carbon and Nitrogen $(\mathrm{C}+\mathrm{N}$; N1); SSM with half strength Carbon and Nitrogen $(C / 2+N / 2$; N2); SSM with full strength Carbon and half strength Nitrogen $(C+N / 2$; N3) in presence of the precursor, $1 \mathrm{mML}$-Trp. To account for the variation caused by the growth, IAA values were normalized to the cell density (OD) in each set and were thus represented as $\mu \mathrm{g} I A A / O D$.

Quantification of PHB production was carried out indirectly based on the principle that the hydrolysis of PHB using concentrated $\mathrm{H}_{2} \mathrm{SO}_{4}$ produces crotonic acid which can be easily quantified by HPLC [76]. Since the production of PHB is maximum during stationary phase, overnight grown wild-type strain, Sp245, grown at three nutritional conditions (N1, N2 and N3) were harvested by centrifuging $10 \mathrm{ml}$ culture at $5000 \times \mathrm{g}$ at $4{ }^{\circ} \mathrm{C}$ for 10 min. The bacterial pellet was resuspended in $1.5 \mathrm{ml}$ sterile distilled water and the cell suspension was transferred to a pre-weighed $2 \mathrm{ml}$ eppendorf tube. The cells were pelleted by centrifuging at $10,000 \times \mathrm{g}$ at $4{ }^{\circ} \mathrm{C}$ for $2 \mathrm{~min}$. 
The cell pellet was stored overnight at $-20^{\circ} \mathrm{C}$ and subsequently lyophilized (up to $16 \mathrm{~h}$ ). The dry cell weight was measured to normalize the amount of PHB, to account for the variation caused by the culture growth. The dry cell pellet was transferred into a borosilicate glass tube and crushed using a spatula after addition of $1 \mathrm{ml}$ concentrated $\mathrm{H}_{2} \mathrm{SO}_{4}$. The glass tube was incubated for $30 \mathrm{~min}$ at $90{ }^{\circ} \mathrm{C}$ in an oven and subsequently cooled on ice. Four $\mathrm{ml} 7 \mathrm{mM} \mathrm{H}_{2} \mathrm{SO}_{4}$ was added to the tube and mixed by vortexing. The sample was diluted 2-folds, filter-sterilized and $10 \mu \mathrm{l}$ aliquot was analysed using HPLC system (Shimadzu, Kyoto, Japan). The sample was analysed based on crotonic acid standards (Sigma-Aldrich, USA), in $30 \%$ acetonitrile in water ( $\mathrm{pH} 2.8$; set with $\mathrm{H}_{3} \mathrm{PO}_{4}$ ) in a reverse-phase column [Luna ${ }^{\circ} 5 \mu \mathrm{m}$ C18(2) $100 \AA, 250 \mathrm{~mm} \times 4.60 \mathrm{~mm}$, Phenomenex, USA] at a flow rate of $0.5 \mathrm{ml} / \mathrm{min}$ at $210 \mathrm{~nm}$ with a UV detector.

Biofilm formation was measured by crystal violet binding assay using the microtitre plate [77]. The bacterial strain was grown overnight in LB medium and $1 \%$ of it was sub-cultured in $10 \mathrm{ml}$ SSM medium. From this, $100 \mu \mathrm{l}$ culture was pipetted in a fresh 96-well microtiter plate, the plate was covered and incubated at $30^{\circ} \mathrm{C}$ for $48 \mathrm{~h}$, under static conditions. Post incubation, the wells were washed thoroughly with sterile, distilled water to remove planktonic bacteria. To each well, $125 \mu \mathrm{l}$ of $0.1 \%$ crystal violet was added and the stain was removed after $10 \mathrm{~min}$ of incubation at RT. The plate was air-dried and $200 \mu \mathrm{L}$ of $95 \%$ ethyl alcohol was added to each stained well to solubilize the dye. The contents of each well were mixed and $125 \mu \mathrm{L}$ of the crystal violet/ ethyl alcohol solution was transferred to a fresh microtitre plate. The absorbance at $560 \mathrm{~nm}$ was measured using Synergy H1 microplate reader (Biotek, USA). All values were normalized with cellular $\mathrm{OD}_{560}$ and hence the biofilm formation was represented as $\mathrm{OD}_{560} /$ cellular $\mathrm{OD}_{560}$.

To estimate the nitrogenase activity, acetylene reduction assay [78] and ethylene produced by the bacteria was used as an indirect method since acetylene is a competitive inhibitor of the nitrogenase enzyme activity. Based on this, glass test tubes $(30 \mathrm{~mL})$ containing $5 \mathrm{~mL}$ of modified SSM media (half- nitrogen and minus nitrogen; $\mathrm{C} / 2+\mathrm{N} / 2, C+\mathrm{N} / 2, \quad \mathrm{C}-\mathrm{N})$ were inoculated with $10 \mu \mathrm{L}$ of adjusted cell suspension. The headspace in the test tube was $25 \mathrm{ml}$. The bacterial cells were grown in the 3 nutrient conditions at $30^{\circ} \mathrm{C}$ for $48 \mathrm{~h}$ (time required to grow the pellicle), the tubes were sealed with a rubber stopper and $1 \mathrm{~mL}$ of acetylene gas was injected into the tubes. Gas samples were removed after an incubation time of $1 \mathrm{~h}$ and assayed for ethylene using a gas chromatograph, equipped with a flame ionization detector and a Porapak N column. The amount of ethylene produced by the bacterial strains was calculated using the ethylene standards and the final amount of gas in $25 \mathrm{ml}$ headspace subsequently obtained. Bacterial cells grown in SSM media $(\mathrm{C}+\mathrm{N})$ were used as control for comparison.

\section{RNA sequencing \\ Total RNA extraction}

The wild-type strain Sp245 was grown under two nutritional conditions: control (VC - SSM with the full strength of nitrogen, N1) and stress-inducing (VN SSM with half strength of nitrogen, N3). The two samples were labelled as $\mathrm{VC}$ and $\mathrm{VN}$, respectively, during the study. Total RNA was extracted using the Ambion PureLink RNA Mini kit (Invitrogen) as per the manufacturer's instructions with certain modifications (for homogenization of the cell lysate, the lysate was centrifuged at $8000 \mathrm{rpm}$ for $2 \mathrm{~min}$ and subsequently proceeded for binding as described in the kit manual). The RNA quantity and quality were determined using the Qubit $^{\circ}$ Fluorometer and Bioanalyzer (Agilent).

\section{cDNA library preparationg and next-generation sequencing (RNA-seq)}

sRNA libraries were constructed for sequencing according to the Illumina TruSeq Small RNA library protocol outlined in "TruSeq Small RNA Sample Preparation Guide" (Part\#15004197Rev.G- December 2014). The prepared library was quantified using Qubit Fluorometer and validated for quality by running an aliquot on the high sensitivity Bioanalyzer Chip (Agilent). The cDNA library was proceeded for sRNA sequencing on an Illumina NextSeq500 platform (Illumina, USA). The sRNA-seq data for both samples, VC and VN, have been submitted to the National Center for Biotechnology Information (NCBI) Gene Expression Omnibus (GEO accession number GSE117764).

\section{RNA-Seq data analysis}

The computational analysis of the RNA-seq output data was carried out as described previously [79] with a few modifications. The quality of the sequencing reads (Fastq output file) was checked using FastQC (Version 0.11.5). The sequences corresponding to the Illumina small $5^{\prime}$ and $3^{\prime}$ adapters (GATCGTCGGACT and TGGAATTCTCGG) were trimmed using CutAdapt [80] and additional filtering was carried out with Trimmomatic (Version 0.36) [81] using default parameters of the software. The quality of the processed output files for both the samples (VC and VN) was again checked using FastQC [82]. Reference-based alignment of the output reads was performed individually for both the samples with Bowtie 2.1.0 [38] using A. brasilense Sp245 (GenBank Assembly accession: GCA_000237365.1) as the reference genome. The mapped reads obtained in the BAM files were filtered on the basis of size i.e.; $50-500 \mathrm{bp}$ 
using an in-house shell script. The data was then analysed for differential gene expression between $\mathrm{VC}$ and VN samples by using Cufflinks (v2.1.1 suite pipeline). Cuffmerge and Cuffdiff tools were used to estimate the transcript abundances and differential gene expression. Cufflinks analysis produced scaled expression in the form of fragments per kilobase per million (FPKM). The statistical significance of the differences in FPKM values in the samples was assessed using the paired Wilcoxon test.

\section{In-silico prediction of novel sRNAs}

sRNAscanner [83] identifies intergenic sRNA transcriptional units in completely sequenced bacterial genomes based on the transcriptional signals. This tool was used to predict sRNAs restricted to the intergenic regions in A. brasilense Sp245 genome with all the parameters set at default values, i.e. 3 provided input matrices: 35box sRNA.matrix (cut-off: 2), 10box_sRNA.matrix (cut-off: 2), terminator.txt.matrix (cut-off: 3); spacer range between [-35] \& [-10] promoter boxes: 12-18; unique hit value: 200; minimum cumulative sum of score (CSS): 14 and sRNA length for prediction: 40-350 nucleotides.

\section{mRNA target prediction}

IntaRNAv2.0, [44] facilitates the process of putative target prediction in bacteria, based on features such as conservation of the sRNA and its accessibility, of the mRNA and hybridization energy. The mRNA targets of the validated sRNAs were predicted using IntaRNAv2.0, with default parameters, i.e. nucleotides (NTs) upstream: 75, NTs Downstream: 75, seed length: 7, sRNA folding window size: 150 , and $P$-value threshold set at 0.05 .

\section{Prediction of secondary structure and homology search}

The secondary structure of the sRNAs was predicted using Mfold web server [84] with default folding temperature of $37^{\circ} \mathrm{C}$. Homology search was carried out for the predicted sRNAs in Bacterial Small Regulatory RNA Database (BSRD) [85] and Rfam database [86]. sRNA with no known homologs were considered as novel sRNAs.

\section{Conserved motifs and promoter prediction}

The conserved motif prediction was carried out using MEME Suite [87] which discovers the novel, ungapped motifs in the nucleotide sequence. Putative promoters and terminator sequences in the predicted sRNA genes were identified using BPROM [43] and FindTerm [88] (software available from SoftBerry), respectively, using default parameters (energy threshold value for FindTerm was -11). BPROM is a bacterial $\sigma 70$ promoter recognition program having high accuracy and specificity while FindTerm recognizes the rho-independent terminators.
sRNA enrichment and northern blot analysis

sRNA enrichment of the isolated RNA preparation from wild-type bacterium $A$. brasilense $\mathrm{Sp} 245$ was carried out by adding $5 \%$ PEG and $0.5 \mathrm{M} \mathrm{NaCl}$ to the sample and incubated overnight at $-80^{\circ} \mathrm{C}$. The sample was centrifuged at maximum speed for $10 \mathrm{~min}$ and to the supernatant, 2.5 volume ethanol (100\%) and one-tenth volume of $3 \mathrm{M}$ sodium acetate was added. After centrifugation at maximum speed for $30 \mathrm{~min}$, the supernatant was discarded, and the pellet was washed with $1 \mathrm{ml}$ ethanol $(80 \%)$. Post drying, the pellet was resuspended in $10 \mu \mathrm{l}$ DEPC water.

The sequences of the probes used for sRNA candidate detection and validation are listed in Additional File 3. The probes were labelled using Biotin DecaLabel DNA Labeling Kit (ThermoFisher Scientific). After electrophoresis on $6 \%$ polyacrylamide gel containing $6 \mathrm{M}$ urea, enriched RNA ( $50 \mu \mathrm{g}$ in each lane) was electrotransferred onto the nitrocellulose membrane. Specific transcripts on the membranes were detected using Biotin Chromogenic Detection kit (ThermoFisher Scientific) according to the manufacturer's instructions.

\section{Quantitative real-time PCRg and expression validation}

Gene expression quantification was performed on a CFX-96 Touch, Real-time PCR detection system (BioRad Labs, Inc.) with 50 ng cDNA template using 2x Sso Fast Eva Green Supermix Dye (Bio-Rad Labs, Inc.) with the manufacturer recommended reaction set-up. The thermal cycling conditions were optimized as per the primers designed for each sRNA and shown in Additional File 7. In each analysis, a No Template Control (NTC) was included and each sample was set up in triplicate. Each plate was repeated at least thrice. Relative gene expression study by qPCR was performed using $16 \mathrm{~S} \mathrm{rDNA}$ as the reference gene for normalization of expression $(\Delta \Delta \mathrm{Cq})$ of each sRNA. The data obtained was further reported in expression fold change in control $(\mathrm{VC})$ versus nitrogen starvation $(\mathrm{VN})$ conditions $\left(2^{\wedge}-\right.$ $\Delta \Delta \mathrm{Cq}$, Fig. 4). The data was statistically analysed for variance by ANOVA followed by Duncan's Post hoc analysis at $P \leq 0.05$. All analysis was performed with Statistical Package for Social Sciences (SPSS ver. 22.0 for Windows).

\section{Supplementary information}

The online version contains supplementary material available at https://doi. org/10.1186/s12864-020-07212-7.

Additional File 1. Table showing the quality check of the raw sRNA sequencing data files.

Additional File 2. Worksheets showing details of the curated, 3860 candidate sRNAs differentially expressed between samples VC and VN, |the 468 candidate sRNAs that conform to the size requirement of 50- 
$500 \mathrm{bp}$ and the 59 candidate sRNAs from the 468 sRNAs that are significantly, differentially expressed between samples VC and VN.

Additional File 3. Northern Blotting for candidate sRNAs. Table 3A Probes used for Northern Blotting and Table 3B - Validation of sRNA expression using northern blot analysis.

Additional File 4. Motifs, promoters and terminators predicted for the 59 significantly differentially expressed sRNAs.

Additional File 5. Details of the targets predicted for the 59 significantly expressed sRNAs. The table highlights target details and score for each category of targets for all sRNAs as well as upregulated/downregulated target mRNA details

Additional File 6. Details of the 14 sRNAs with no InterProScan hits and their respective mRNA target categories and scores.

Additional File 7. Details of Sixteen sRNAs validated by qRT-PCR based differential expression analysis.

\section{Abbreviations}

SRNA: small RNA; FPKM: Fragments per kilobase transcript per million mapped reads; BSRD: Bacterial Small Regulatory RNA; SAM: Sequence alignment map; RIN: RNA Integrity Number; PHB: Polyhydroxybutyrate; PGPB: Plant Growth-Promoting Bacteria; PAB: Plant associated bacteria

\section{Acknowledgements}

The authors are thankful to the TERI-Deakin Nanobiotechnology Research Centre for providing the necessary infrastructure to carry out required research work. Authors also wish to thank Ms. Deepti Varshney for her inputs on RNA-seq data analysis.

\section{Authors' contributions}

The overall work strategy and experiments were designed by VK, PS and MK. VK carried out most of the experiments and supported RNA sequencing data analysis. DS performed RNA sequencing analysis in consultation with PS and MK. PS and MK wrote the manuscript and MK carried out some experiments. All authors have read and approved the final manuscript.

\section{Funding}

This work was supported by the Science and Engineering Research Board (SERB), Government of India Core Research Grant to MK (EMR/2016/002657). The funders had no role in study design, data collection and interpretation, writing the manuscript and the decision to submit the work for publication.

\section{Availability of data and materials}

The small RNA-seq data has been submitted to the National Center for Biotechnology Information (NCBI) Gene expression Omnibus (GEO) with accession number GSE117764.

\section{Ethics approval and consent to participate}

Not applicable.

\section{Consent for publication}

Not applicable.

\section{Competing interests}

The authors declare that they have no competing interests.

\section{Author details}

'The Energy and Resources Institute, Darbari Seth Block, India Habitat Centre, Lodhi Road, New Delhi 110003, India. ${ }^{2}$ TERI Deakin Nanobiotechnology Centre, Sustainable Agriculture Division, The Energy and Resources Institute, Gurugram-Faridabad Road, Gwal Pahari, Haryana 122003, India.

Received: 17 December 2019 Accepted: 5 November 2020 Published online: 23 November 2020

\section{References}

1. Sharon FP, Saul B, Yaacov O. Key physiological properties contributing to rhizosphere adaptation and plant growth promotion abilities of Azospirillum brasilense. FEMS Microbiol Lett. 2012;2:99-108.
2. Koul V, Adholeya A, Kochar M. Sphere of influence of indole acetic acid and nitric oxide in bacteria. J Basic Microbiol. 2015a;55:543-53.

3. Spaepen S, Vanderleyden J, Remans R. Indole-3-acetic acid in microbial and microorganism-plant signaling. FEMS Microbiol Rev. 2007;31:425-48.

4. Molina FC, Cecilia MC, Marcela S, Susana P, Lorenzo L. Aerobic nitric oxide production by Azospirillum brasilense Sp245 and its influence on root architecture in tomato. Mol Plant Microbe Interact. 2008;21:1001-9.

5. De-Bashan LE, Bashan Y. Immobilized microalgae for removing pollutants: review of practical aspects. Bioresour Technol. 2010;101:1611-27.

6. Koul V, Tripathi C, Adholeya A, Kochar M. Nitric oxide metabolism and indole acetic acid biosynthesis cross-talk in Azospirillum brasilense SM. Res Microbiol. 2015b;166:174-85.

7. Fukami J, Cerezini P, Hungria M. Azospirillum: benefits that go far beyond biological nitrogen fixation. AMB Express. 2018;8:73.

8. Wisniewski-Dyé F, Borziak K, Khalsa-Moyers G, Alexandre G, Sukharnikov LO,

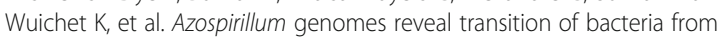
aquatic to terrestrial environments. PLoS Genet. 2011;7:e1002430.

9. Wisniewski-Dyé F, Lozano L, Acosta-Cruz E, Borland S, Drogue B, PrigentCombaret C, et al. Genome sequence of Azospirillum brasilense CBG497 and comparative analyses of Azospirillum Core and accessory genomes provide insight into niche adaptation. Genes. 2012;3:576-602.

10. Fibach-Paldi S, Burdman S, Okon Y. Key physiological properties contributing to rhizosphere adaptation and plant growth promotion abilities of Azospirillum brasilense. FEMS Microbiol Lett. 2012;326:99-108.

11. de Zelicourt A, Al-Yousif M, Hirt H. Rhizosphere microbes as essential partners for plant stress tolerance. Mol Plant. 2013;6:242-5.

12. Nadeem SM, Ahmad M, Zahir ZA, Javaid A, Ashraf M. The role of mycorrhizae and plant growth promoting rhizobacteria (PGPR) in improving crop productivity under stressful environments. Biotechnol Adv. 2014;32: 429-48.

13. Ngumbi E, Kloepper J. Bacterial-mediated drought tolerance: current and future prospects. Appl Soil Ecol. 2016;105:109-25.

14. Storz G, Vogel J, Wassarman KM. Regulation by small RNAs in bacteria: expanding frontiers. Mol Cell. 2011;43:880-91.

15. Adler C, Corbalan NS, Peralta DR, Pomares MF, de Cristóbal RE, Vincent PA. The alternative role of Enterobactin as an oxidative stress protector allows Escherichia coli Colony development. PLoS One. 2014;9:e84734.

16. Gottesman S, Storz G. Bacterial small RNA regulators: versatile roles and rapidly evolving variations. Cold Spring Harb Perspect Biol. 2011;3:12.

17. Tsai CH, Liao R, Chou B, Palumbo M, Contreras LM. Genome-wide analyses in bacteria show small-RNA enrichment for long and conserved intergenic regions. J Bacteriol. 2015;197:40-50.

18. Storz G, Opdyke JA, Zhang A. Controlling mRNA stability and translation with small, noncoding RNAs. Curr Opin Microbiol. 2004;7:140-4.

19. Storz G, Altuvia S, Wassarman KM. An abundance of RNA regulators. Annu Rev Biochem. 2005;74:199-217.

20. Altuvia S. Identification of bacterial small non-coding RNAs: experimental approaches. Curr Opin Microbiol. 2007;10:257-61.

21. Delihas N. Small regulatory RNAs in Bacteria. Wiley; 2016.

22. Khoo JS, Chai SF, Mohamed R, Nathan S, Firdaus-Raih M. Computational discovery and RT-PCR validation of novel Burkholderia conserved and Burkholderia pseudomallei unique sRNAs. BMC Genomics. 2012;13:7-13.

23. Wagner EGH, Romby P. Small RNAs in bacteria and archaea: who they are, what they do, and how they do it. Adv Genet. 2015;90:133-208.

24. Gottesman S. Micros for microbes: non-coding regulatory RNAs in bacteria. Trends Genet. 2005;21:399-404.

25. Vogel J, Papenfort K. Small non-coding RNAs and the bacterial outer membrane. Curr Opin Microbiol. 2006;9:605-11.

26. Massé E, Gottesman S. A small RNA regulates the expression of genes involved in iron metabolism in Escherichia coli. Proc Natl Acad Sci U S A. 2002;99:4620-5.

27. Lenz DH, Mok KC, Lilley BN, Kulkarni RV, Wingreen NS, Bassler BL. The small RNA chaperone $\mathrm{Hfq}$ and multiple small RNAs control quorum sensing in Vibrio harveyi and Vibrio cholerae. Cell. 2004;118:69-82.

28. Chambers JR, Sauer K. Small RNAs and their role in biofilm formation. Trends Microbiol. 2013;21(1):39-49.

29. Valverde C, Livny J, Schlüter JP, Reinkensmeier J, Becker A, Parisi G. Prediction of Sinorhizobium meliloti sRNA genes and experimental detection in strain 2011. BMC Genomics. 2008;9:416-30.

30. Torres-Quesada O, Oruezabal RI, Peregrina A, Jofré E, Lloret J, Rivilla R, Toro $\mathrm{N}$, Jiménez-Zurdo Jl. The Sinorhizobium meliloti RNA chaperone Hfa 
influences central carbon metabolism and the symbiotic interaction with alfalfa. BMC Microbiol. 2010;10:71-92.

31. Madhugiri R, Pessi G, Voss B, Hahn J, Sharma CM, Reinhardt R, et al. Small RNAs of the Bradyrhizobium/ Rhodopseudomonas lineage and their analysis. RNA Biol. 2012;9:47-58

32. Torres-Quesada O, Millán V, Nisa-Martínez R, Bardou F, Crespi M, Toro N, et al. Independent activity of the homologous small regulatory RNAs AbcR1 and AbcR2 in the legume symbiont Sinorhizobium meliloti. PLoS One. 2013; 8:e68147.

33. Torres-Quesada O, Reinkensmeier J, Schlüter JP, Robledo M, Peregrina A, Giegerich R, et al. Genome-wide profiling of Hfq-binding RNAs uncovers extensive post-transcriptional rewiring of major stress response and symbiotic regulons in Sinorhizobium meliloti. RNA Biol. 2014;11:563-79.

34. Fan B, Li L, Chao Y, Förstner K, Vogel J, Borriss R, Wu XQ. dRNA-Seq reveals genome-wide TSSs and noncoding RNAs of plant beneficial Rhizobacterium Bacillus amyloliquefaciens FZB42. PLoS One. 2015;10:e0142002.

35. Bashan Y, Holguin G. Azospirillum-plant relationships: environmental and physiological advances (1990-1996). Can J Microbiol. 1997;43:103-21.

36. Malhotra M, Srivastava S. Stress-responsive indole-3-acetic acid biosythesis by Azospirillum brasilense SM and its ability to modulate plant growth. Eur J Soil Biol. 2009;45:73-80.

37. Kochar M, Srivastava S. Surface colonization by Azospirillum brasilense SM in the indole-3-acetic acid dependent growth improvement of sorghum. J Basic Microbiol. 2012:52:123-31.

38. Langmead B, Salzberg S. Fast gapped-read alignment with Bowtie2. Nat Methods. 2012;9:357-9.

39. Gupta S, Stamatoyannopoulos JA, Bailey TL, Noble WS. Quantifying similarity between motifs. Genome Biol. 2007;8:R24.

40. Cody WL, Pritchett $C L$, Jones AK, Carterson AJ, Jackson D, Frisk A, et al. Pseudomonas aeruginosa AlgR controls cyanide production in an AlgZdependent manner. J Bacteriol. 2009;191:2993-3002.

41. Shimada T, Ishihama A, Busby SJ, Grainger DC. The Escherichia coli RutR transcription factor binds at targets within genes as well as intergenic regions. Nucleic Acids Res. 2008;36:3950-5.

42. Chatterjee A, Cui Y, Hasegawa H, Chatterjee AK. PsrA, the Pseudomonas sigma regulator, controls regulators of epiphytic fitness, quorum-sensing signals, and plant interactions in Pseudomonas syringae pv. Tomato strain DC3000. Appl Environ Microbiol. 2007;73:3684-94.

43. BPROM: http://www.softberry.com/berry.phtml?topic=bprom/. Accessed 6 Feb 2019

44. Martin M, Patrick RW, Rolf B. IntaRNA 2.0: enhanced and customizable prediction of RNA-RNA interactions. Nucleic Acids Res. 2017:45:W435-9.

45. Shippy DC, Amin AF. tRNA modification enzymes GidA and MnmE: potential role in virulence of bacterial pathogens. Int J Mol Sci. 2014;15: 18267-80.

46. Dimkpa C, Weinand T, Asch F. Plant-rhizobacteria interactions alleviate abiotic stress conditions. Plant Cell Environ. 2009;32:1682-94.

47. Malhotra M, Srivastava S. Organization of the ipdC region regulates IAA levels in different Azospirillum brasilense strains: molecular and functional analysis of ipdC in strain SM. Environ Microbiol. 2008a;10:1365-73.

48. Kamnev AA, Sadovnikova JN, Tarantilis PA, Moschos GP, Lyudmila PA. Responses of Azospirillum brasilense to nitrogen deficiency and to wheat Lectin: a diffuse reflectance infrared Fourier transform (DRIFT) spectroscopic study. Microb Ecol. 2008;56:615.

49. Grabowicz M, Silhavy TJ. Envelope stress responses: an interconnected safety net. Trends Biochem Sci. 2017;42:232-42.

50. Gómez-Lozano M, Marvig RL, Tulstrup MV, Molin S. Expression of antisense small RNAs in response to stress in Pseudomonas aeruginosa. BMC Genomics. 2014;15:783-92.

51. Gómez-Lozano M, Marvig RL, Molina-Santiago C, Tribelli PM, Ramos JL, Molin S. Diversity of small RNAs expressed in Pseudomonas species. Environ Microbiol Rep. 2015;7:227-36.

52. McClure R, Tjaden B, Genco C. Identification of sRNAs expressed by the human pathogen Neisseria gonorrhoeae under disparate growth conditions. Front Microbiol. 2014;5:456-68.

53. Amin SV, Roberts JT, Patterson DG, Coley AB, Allred JA, Denner JM, et al. Novel small RNA (sRNA) landscape of the starvation-stress response transcriptome of Salmonella enterica serovar typhimurium. RNA Biol. 2016; 13:331-42.
54. Tesorero RA, Yu N, Wright JO, Svencionis JP, Cheng Q, Kim JH, et al. Novel regulatory small RNAs in Streptococcus pyogenes. PLoS One. 2013;8(6): e64021.

55. McClure R, Balasubramanian D, Sun Y, Bobrovskyy M, Sumby P, Genco CA, et al. Computational analysis of bacterial RNA-Seq data. Nucleic Acids Res. 2013:41:e140.

56. Liu JM, Livny J, Lawrence MS, Kimball MD, Waldor MK, Camilli A. Experimental discovery of sRNAs in Vibrio cholerae by direct cloning, 5S/ tRNA depletion and parallel sequencing. Nucleic Acids Res. 2009;37:e46.

57. Papenfort K, Förstner KU, Cong JP, Sharma CM, Bassler BL. Differential RNAseq of Vibrio cholera identifies the VqmR small RNA as a regulator of biofilm formation. Proc Natl Acad Sci U S A. 2015;112:E766-75.

58. Mitschke J, Georg J, Scholz I, Sharma CM, Dienst D, Bantscheff J, et al. An experimentally anchored map of transcriptional start sites in the model cyanobacterium Synechocystis sp. PCC6803. Proc Natl Acad Sci U S A. 2011; 108:2124-9.

59. Raja I, Kumar V, Sabapathy H, Kumariah M, Rajendran K, Tennyson J. Prediction and identification of novel sRNAs involved in Agrobacterium strains by integrated genome-wide and transcriptome-based methods. FEMS Microbiol Lett. 2018;1:365.

60. Schlüter JP, Reinkensmeier J, Daschkey S, Evguenieva-Hackenberg E, Janssen $\mathrm{S}$, Janicke $\mathrm{S}$, et al. A genome-wide survey of sRNAs in the symbiotic nitrogen-fixing alpha-proteobacterium Sinorhizobium meliloti. BMC Genomics. 2010;11:245-80

61. Wilderman PJ, Sowa NA, FitzGerald DJ, FitzGerald PC, Gottesman S, Ochsner $U A$, et al. Identification of tandem duplicate regulatory small RNAs in Pseudomonas aeruginosa involved in iron homeostasis. Proc Natl Acad Sci U S A. 2004;101:9792-7.

62. Reinhart AA, Powell DA, Nguyen AT, O'Neill M, Djapgne L, Wilks A, et al. The prrF-encoded small regulatory RNAs are required for iron homeostasis and virulence of Pseudomonas aeruginosa. Infect Immun. 2015;83(3):863-75.

63. Rossi CC, Bossé JT, Li Y, Witney AA, Gould KA, Langford PR, et al. A computational strategy for the search of regulatory small RNAs in Actinobacillus pleuropneumoniae. RNA. 2016;22(9):1373-85.

64. Simm R, Morr M, Kader A, Nimtz M, Römling U. GGDEF and EAL domains inversely regulate cyclic di-GMP levels and transition from sessility to motility. Mol Microbiol. 2004;53:1123-34.

65. Mata AR, Pacheco CM, Cruz Pérez JF, Sáenz MM, Baca BE. In silico comparative analysis of GGDEF and EAL domain signaling proteins from the Azospirillum genomes. BMC Microbiol. 2018;18:20.

66. Sarenko O, Klauck G, Wilke FM, Pfiffer V, Richter AM, Herbst S, et al. More than enzymes that make or break Cyclic Di-GMP_local signaling in the interactome of GGDEF/EAL domain proteins of Escherichia coli. mBio. 2017; 8:e01639-17.

67. Tjaden B. Biocomputational identification of bacterial small RNAs and their target binding sites. In: Mallick B, Ghosh Z, editors. Regulatory RNAs. New York: Springer; 2012. p. 273-93.

68. Morita T, Ueda M, Kubo K, Aiba H. Insights into transcription termination of Hfq-binding sRNAs of Escherichia coli and characterization of read through products. RNA. 2015;21:1490-501.

69. Otaka H, Ishikawa H, Morita T, Aiba H. PolyU tail of rho-independent terminator of bacterial small RNAs is essential for $\mathrm{Hfa}$ action. Proc Natl Acad Sci U S A. 2011;108:13059-64.

70. Hallier M, Chabelskaya S, Felden B. Experimental analyses of RNA-based regulations in Bacteria. In: Mallick B, Ghosh Z, editors. Regulatory RNAs. New York: Springer; 2012. p. 341-70.

71. Kumar R, Shah P, Swiatlo E, Burgess SC, Lawrence ML, Nanduri B. Identification of novel non-coding small RNAs from Streptococcus pneumoniae TIGR4 using high-resolution genome tiling arrays. BMC Genomics. 2010;11:350-69.

72. Brosse A, Korobeinikova A, Gottesman S, Guillier M. Unexpected properties of sRNA promoters allow feedback control via regulation of a twocomponent system. Nucleic Acids Res. 2016:44:9650-66.

73. Bashan $Y$, Holguin $G$, Lifshitz R. Isolation and characterization of plant growth-promoting rhizobacteria. In: Glick BR, Thompson JE, editors. Methods in plant molecular biology and bio- technology. Boca Raton: CRC Press; 1993. p. 331-45.

74. Meyer JM, Abdallah MA. The fluorescent pigment of Pseudomonas fluorescens: biosynthesis, purification and physicochemical properties. J Gen Microbiol. 1978;107:319-28. 
75. Malhotra M, Srivastava S. Targeted engineering of Azospirillum brasilense strain SM with indole acetamide pathway for IAA overexpression. Can J Microbiol. 2006;52:1078-84.

76. Müller-Santos M, de Souza EM, de Oliveira PF, Chubatsu LS.

Polyhydroxybutyrate in Azospirillum brasilense. In: Cassan FD, Okon Y, Creus CM, editors. Handbook for Azospirillum. Switzerland: Springer International Publishing; 2015. p. 241-50

77. Merritt JH, Kadouri DE, O'Toole GA. Growing and analyzing static biofilms. Curr Protoc Microbiol. 2005. https://doi.org/10.1002/9780471729259. mc01b01s.

78. Boddey R. Methods for quantification of nitrogen fixation associated with gramineae. Crit Rev Plant Sci. 1987;6:209-66.

79. Heera R, Sivachandran P, Chinni SV, Mason J, Croft L, Ravichandran M, et al. Efficient extraction of small and large RNAs in bacteria for excellent total RNA sequencing and comprehensive transcriptome analysis. BMC Res Notes. 2015;8:754-65.

80. Martin M. Cutadapt removes adapter sequences from high-throughput sequencing reads. EMBnet J. 2011;17:10-2.

81. Bolger AM, Lohse M, Usadel B. Trimmomatic: a flexible trimmer for Illumina sequence data. Bioinformatics. 2014;30:2114-20.

82. Andrews S. FastQC: a quality control tool for high throughput sequence data. 2010. (http://www.bioinformatics.babraham.ac.uk/projects/fastqc), Accessed 4 Nov 2018.

83. Sridhar J, Narmada SR, Sabarinathan R, Ou H-Y, Deng Z. sRNAscanner: a computational tool for intergenic small RNA detection in bacterial genomes. PLoS One. 2010:5:e11970

84. Zuker M. Mfold web server for nucleic acid folding and hybridization prediction. Nucleic Acids Res. 2003;31:3406-15.

85. Li L, Huang DD, Cheung MK, Nong WY, Huang QL, Kwan HS. BSRD: a repository for bacterial small regulatory RNA. Nucleic Acids Res. 2013;41: 233-8.

86. Nawrocki EP, Burge SW, Bateman A, Daub J, Rberhardt RY, Eddy SR, et al. Rfam 12.0: updates to the RNA families database. Nucleic Acids Res. 2015;43: D130-7.

87. Bailey $T L$, Elkan C. Fitting a mixture model by expectation maximization to discover motifs in biopolymers. Proc Int Conf Intell Syst Mol Biol. 1994;2:2836.

88. Solovyev V, Salamov A. In: Li RW, editor. Metagenomics and its Applications in Agriculture, Biomedicine and Environmental Studies. Hauppauge, NY: Nova Science Publishers; 2011. p. 61-78.

\section{Publisher's Note}

Springer Nature remains neutral with regard to jurisdictional claims in published maps and institutional affiliations.

Ready to submit your research? Choose BMC and benefit from:

- fast, convenient online submission

- thorough peer review by experienced researchers in your field

- rapid publication on acceptance

- support for research data, including large and complex data types

- gold Open Access which fosters wider collaboration and increased citations

- maximum visibility for your research: over $100 \mathrm{M}$ website views per year

At $\mathrm{BMC}$, research is always in progress.

Learn more biomedcentral.com/submissions 